\title{
The Golden 1,000 Days
}

\section{Carlo V Bellieni*}

University Hospital, Le Scotte, Viale M Bracci, Siena 53100, Italy

*Corresponding author: Carlo V Bellieni, University Hospital, Le Scotte, Viale M Bracci, Siena 53100, Italy, Tel: +390577586550; Fax: +390577586182; E-mail: cvbellieni@gmail.com

Rec date: Apr 17, 2016; Acc date: Apr 24, 2016; Pub date: Apr 29, 2016

Copyright: ( 2016 Bellieni CV. This is an open-access article distributed under the terms of the Creative Commons Attribution License, which permits unrestricted use, distribution, and reproduction in any medium, provided the original author and source are credited.

\begin{abstract}
The first 1,000 days, from conception to the end of the second year after birth, are crucial for the future of any human being. They are crucial for health, for the development of diseases, for learning. In this process, epigenetics and precocious sensory development are the principal routes. Several organizations throughout the globe have highlighted the importance of these 1,000 days. The "1,000 Days" initiative was born in 2010 with the backing of the U.S. Government, the Government of Ireland and several nonprofit organizations, and drove greater action and investment to improve nutrition for women and young children throughout the world. This and similar initiatives aim to improve nutrition in developing and in industrialized countries, where problems are different, but the first 1,000 days are equally crucial; these initiatives are highlighted in the text.
\end{abstract}

\section{Introduction}

Recently, increasing data about the long-term impact of nutrition in gestation and in early childhood [1] on psychosocial functioning and productivity has stimulated "first 1000 days" campaigns dealing with global health policy [2,3]. In fact, 1,000 days stand between a woman's pregnancy and her child's second birthday that can shape his/her future health; this concept has more and more acquired evidence and importance. The correct nutrition in this period has a deep impact on a child's ability to grow, learn, and thrive.

The UNICEF-sponsored "Golden 1000 Days" initiative, carried out by Nepal Ministry of Health and Population, revealed that the nutrition situation-namely among young children under two years of age-is quite poor, with deep, lifelong and irreversible consequences on their future. About forty percent of the children are stunted for chronic malnutrition), and ten percent of them are wasted for acute malnutrition. This analysis on nutrition showed that growth flaws are particularly frequent during the first two years after birth; some improvements have been introduced in their died, namely vitamin A and iodine, and anemia has been more effectively treated though it still remains a critical problem, which affects more than one-and-a-half million under-five children, mostly in their first biennium [4]. Thus, if we do not intervene in the first 1,000 days of life, it is too late.

However, 1,000-days campaigns are not only on under nutrition. One was launched in Poland: the "1,000 days for health" is a donation grant for Food Banks. Organized by Nutricia Foundation in partnership with the Federation of Polish Food Banks. This donation grant is a part of the social national campaign. The aim of the project is to popularize positive eating habits among pregnant women and young children, and change the negative trends related to diet [5]. Similarly, a panel of Italian, Spanish and French experts, the Mediterranean Nutrition Group, recently published a document called the Milan Chart [6] that outlines the importance of the nutrition in the first 1,000 days, in order to prevent overweight and obesity.

In those crucial 1,000 days, epigenetic persistent changes can occur and can condition the rest of a human's life. Epigenetics is the way environment influences the expression of DNA; it does not alter the
DNA sequence, but it can be heritable [7], changes include DNA methylation, histone modifications, and chromatin remodeling. Many fine studies have shown the influence of environment on DNA for embryonic development; but also for the future development of obesity or diabetes, for the development of stress responses, of hypertension or cancer. Therefore epigenetic modifications are to be considered an important mechanism in the etiology of many diseases since the prenatal life [8]. Such induced epigenetic changes can be inherited during cell division in the first phases of life, namely in the first part of the golden 1,000 days, resulting in permanent conservation of the acquired phenotype. In the nutritional field, epigenetics is hugely important, because nutrients and bioactive food components can modify epigenetic manifestations of DNA and consequently the expression of genes during their transcription [9]. Experiments in mice show how important a mother's diet is in building the epigenome of her offspring. All mammals have a gene called agouti (i.e., banded). When this gene is not methylated, mice's coat is yellow and they are obese and risks developing diabetes and cancer. But when this gene is methylated (as it happens in common mice), the coat is brown and the mouse are healthier [10]. Fat yellow mice and skinny brown mice are genetically identical, but the former have an epigenetic alteration that can be reversed feeding them with a diet rich of methyl groups. Thus, their health is not only determined by what they ate, but also what their parents ate. Pollutants also can affect the epigenome, in particular at the very immature state of life. Bisphenol A (BPA) is used to make polycarbonate plastic; it is manufactured in many products, including water bottles and tin cans and can reduce the methylation of the agouti gene $[11,12]$. When mothers were fed BPA, their babies were more likely to be yellow and obese. However, when mothers were fed BPA along with methyl-rich foods, the offspring were more likely to be brown and healthy. The maternal nutrient supplementation had balanced the bad effects of BPA.

Diet in the first stages of life can have detrimental consequences, but it also shapes and imprints us for a lot of personal features and preferences. The analysis of our epigenome provides a lot of information on our previous diet habits: nutrigenomics is an emerging science which studies the different responses individuals have to 
different diets; in the future nutritionists will have the chance to know one's methylation data and consequently his/her diet story, to design a personalized nutrition plan [13]. Human food preferences receive an imprinting in prenatal life, i.e., in the first part of those fatidic 1,000 days, as the fetus receives tastes and habituates to maternal nutrients, derived from maternal alimentation, through the placenta and the amniotic liquid.

Thus, the correct nutrition during this 1,000 day window has a profound impact on a child's ability to grow, learn and thrive-and therefore it has a lasting effect on a country's health and prosperity. Unfortunately, the first 1000 days of everyone's life do not yet receive correct relevance. Even newborns' rights are often devaluated when compared to those of older children or adults. Annie Janvier and colleagues analyzed surveys for about 700 neonatologists and obstetricians. As they expected, in most cases there were inverse relationships between valuation of best interest of babies and older patients: babies' were systematically devaluated [14]. Other authors described other issues where neonatal life is devaluated, e.g. pain treatment or the right to their parents' presence in hospital [15]. Even from a psychological point of view, the first 1000 days are crucial. Prenatal stress and suffering will mark the future of the person; maternal stress or depression in pregnancy affects the foetus and this should be known to preventively take care of the metal state of the baby after birth. A lack of maternal comfort can disrupt babies' brain and the high level of painful procedures a baby goes through in many NICUs can alter their brain unless a correct developmental care is undergone. A randomized clinical trial tested the neurodevelopmental effectiveness of the New born Individualized Developmental Care and Assessment Program (NIDCAP), a particular strategy to increase the chances of a better future development through a balanced and wellorganized care of the infant [16]. Thirty preterm infants participated in the trial. Control and experimental infants were evaluated at two weeks' and nine months' corrected age about their health status, growth, and neuro behavior, and at two weeks' corrected age additionally to assess electroencephalographic (EEG) and magnetic resonance imaging (MRI). The groups were medically and demographically similar, but the experimental group developed significantly better neurobehavioral skills and EEG-MRI features. Behaviour was improved also at 9 months' corrected age. This indicates consistently better neurological function for infants who received a structured care in the first stages of development.

The "1,000 golden days" campaign can be enjoyed via the site www.thousanddays.org. Its aim is to improve nutrition for the most vulnerable and in some of the poorest parts of the world; malnutrition constitutes a serious public health crisis in nearly every country on earth. It recently expanded its work to build partnerships and efforts to bring attention to the issues of poor nutrition, food insecurity and obesity that are impacting the future health and well-being of America's youngest children, because the long-term benefits of a healthy 1,000-day window can't be underemphasized. The impact of good nutrition early in life can reach far into the future. Children who get the right nutrition in their first 1,000 days are ten times more likely to overcome life-threatening childhood diseases, complete nearly five more grades in school, go on to earn $21 \%$ more in wages as adults and are more likely to have healthier families of their own.

Fetal nutrition during pregnancy and that of a child in the first two years of life provide the essential bricks for brain development, healthy growth and a strong immune system. Research shows that the foundations of a person's lifelong health-e.g. their predisposition to obesity and certain chronic diseases-are largely set during this 1,000 day window; thus it is critical that women and children get the right nutrition during this time.

Malnutrition early in life is ominous and governments that tolerate it are inexcusable. Malnutrition in the first 1000 days can cause irreversible damage to children's brain and their physical growth, provoking a reduced capacity to learn, poorer performance in school, greater susceptibility to infection and diseases, and lower earning potential. It even increases the risk of developing illnesses like heart disease, diabetes and certain types of cancers later in life. The impact of poor nutrition early in life has lasting effects that can be trans generational and that can manifest themselves throughout the world: malnourished women give birth to malnourished daughters who grow up and become malnourished mothers, perpetuating the cycle. Health hazards by malnutrition during the first years of a child's life become a serious economic problem for countries, costing billions of dollars in lost productivity and avoidable health care costs. But by improving nutrition during the crucial first 1,000 days, much of the serious and irreparable problems caused by hunger and malnutrition can be prevented.

The rules to follow in the first 1,000 days are simple and they are reliable for developed and for developing countries. Pregnant women should receive adequate amount and variety of nutrients, including the necessary supplement of folic acid to prevent fetal spina bifida. After birth, women should continue to be in a privileged feeding regimen even in places of famine and war and breastfeeding should be encouraged, since breastfeeding is an unequalled way of providing ideal food for the healthy growth and development of infants. Infants should be exclusively breastfed for the first six months of life to achieve optimal growth, development and health. Thereafter, to meet their evolving nutritional requirements, infants should receive nutritionally adequate and safe complementary foods while breastfeeding-in particular conditions-continues for up to two years of age or beyond [17], and a safe pollution-free food should be guaranteed. These easy recommendations endorsed by the world Health Organization should be granted everywhere: the future of the next generation has here its bases.

\section{References}

1. Tomlinson M (2015) Infant mental health in the next decade: A call for action. Infant Ment Health J 36: 538-541.

2. Worthman CM, Tomlinson M, Rotheram-Borus MJ (2016) When can parents most influence their child's development? Expert knowledge and perceived local realities. Soc Sci Med 154: 62-69.

3. Krishna A, Fink G, Berkman LF, Subramanian SV (2016) Short- and long-run associations between birth weight and children's height. Econ Hum Biol 21: 156-166.

4. (2011) UNICEF Golden 1000 days flier.

5. (2016) Nutricia Foundation, Food Banks from Olsztyn and Lodz, Federation of Polish Food Banks: The first "1,000 days for health" grant for food bank.

6. (2015) Mediterranean Nutrition Group. Carta di Milano.

7. Whayne TF (2015) Epigenetics in the development, modification, and prevention of cardiovascular disease. Mol Biol Rep 42: 765-776.

8. Zhang Y, Ren J (2016) Epigenetics and obesity cardiomyopathy: From pathophysiology to prevention and management. Pharmacol Ther 161: 52-66.

9. Choi SW, Friso S (2010) Epigenetics: A New Bridge between Nutrition and Health. Adv Nutr 1: 8-16. 
10. Oey H, Isbel L, Hickey P, Ebaid B, Whitelaw E (2015) Genetic and epigenetic variation among inbred mouse littermates: identification of inter-individual differentially methylated regions. Epigenetics Chromatin.

11. Wang T, Han J, Duan X, Xiong B, Cui XS, et al. (2016) The toxic effects and possible mechanisms of Bisphenol $\mathrm{A}$ on oocyte maturation of porcine in vitro. Oncotarget.

12. Singh S, Li SS (2012) Epigenetic effects of environmental chemicals bisphenol A and phthalates. Int J Mol Sci 13: 10143-10153.

13. Ferguson JF, Allayee H, Gerszten RE, Ideraabdullah F, Kris-Etherton PM et al. (2016) Nutrigenomics, the Microbiome, and Gene-Environment Interactions: New Directions in Cardiovascular Disease Research, Prevention, and Treatment: A Scientific Statement From the American Heart Association. Circ Cardiovasc Genet.
14. Laventhal N, Spelke MB, Andrews B, Larkin LK, Meadow W, et al. (2011) Ethics of resuscitation at different stages of life: a survey of perinatal physicians. Pediatrics 127: e1221-e1229.

15. Bellieni CV, Tei M, Coccina F, Buonocore G (2012) Why do we treat the newborn differently? J Matern Fetal Neonatal Med 25: 73-75.

16. Als H, Duffy FH, McAnulty GB, Rivkin MJ, Vajapeyam S, et al. (2004) Early experience alters brain function and structure. Pediatrics 113: 846-857.

17. Wen LM, Simpson JM, Rissel C, Baur LA (2012) Awareness of breastfeeding recommendations and duration of breastfeeding: findings from the Healthy Beginnings Trial. Breastfeed Med 7: 223-229. 